\title{
Effect Of Magnesium Perchlorate Content on the Mechanical, Thermal Stability, and Dielectric Properties of Plasticized PMMA/PVC-g-PMMA Electrolytes
}

\author{
Nguyen Thi Kim Dung, ${ }^{1}$ Nguyen Thi Dieu Linh, ${ }^{2}$ Do Quang Tham $\mathbb{D},{ }^{3,4}$ \\ Nguyen Thuy Chinh, ${ }^{3}$ Man Minh Tan, ${ }^{5,6}$ Tran Thi Mai, ${ }^{3}$ Nguyen Thi Thu Trang, ${ }^{3}$ \\ Do Minh Thanh, ${ }^{3}$ Nguyen Quang Tung, ${ }^{2}$ and Thai Hoang ${ }^{3}$ \\ ${ }^{1}$ National Institute of Education Management, Thanh Xuan, Hanoi 10000, Vietnam \\ ${ }^{2}$ Faculty of Chemical Technology, HaUI, Tay Tuu, North Tu Liem, Hanoi 10000, Vietnam \\ ${ }^{3}$ Institute for Tropical Technology, VAST, 18 Hoang Quoc Viet, Nghia Do, Cau Giay, Hanoi 10072, Vietnam \\ ${ }^{4}$ Graduate University of Science and Technology, VAST, 18 Hoang Quoc Viet, Nghia Do, Cau Giay, Hanoi 10072, Vietnam \\ ${ }^{5}$ Institute of Theoretical and Applied Research, Duy Tan University, Hanoi 100000, Vietnam \\ ${ }^{6}$ Faculty of Natural Sciences, Duy Tan University, Da Nang 550000, Vietnam
}

Correspondence should be addressed to Do Quang Tham; dqtham@itt.vast.vn

Received 17 July 2020; Revised 24 October 2020; Accepted 29 October 2020; Published 16 November 2020

Academic Editor: Viet Hai Le

Copyright ( 2020 Nguyen Thi Kim Dung et al. This is an open access article distributed under the Creative Commons Attribution License, which permits unrestricted use, distribution, and reproduction in any medium, provided the original work is properly cited.

\begin{abstract}
In this study, new types of gel polymer blend electrolytes (GPBEs) were prepared with the synthesized PVC-g-PMMA graft copolymer, PMMA, plasticizers (propylene carbonate (PC), dioctyl phthalate (DOP)), and different loadings of $\mathrm{Mg}\left(\mathrm{ClO}_{4}\right)_{2}$ via the solution casting method using tetrahydrofuran as solvent. Fourier transform infrared (FTIR) spectra of the electrolytes showed mutual molecular interactions between $\mathrm{Mg}\left(\mathrm{ClO}_{4}\right)_{2}$ and organic moieties. The scanning electron microscopy images of the GPBEs showed their wrinkled surface morphology due to their low elastic modulus and high flexibility. Energy-dispersive Xray (EDX) spectroscopy and mapping technique revealed the regular distributions of all atomic elements such as $\mathrm{Cl}, \mathrm{Mg}, \mathrm{O}$, and $\mathrm{C}$ in the doped GPBEs. With increasing the Mg salt concentration, Young's modulus and tensile strength of the GPBEs strongly decreased. Interestingly, the elongation at break of the GPBEs was higher than that of neat (undoped) GPBE and achieved the highest value of $215 \%$ at the salt content of $20 \mathrm{wt} . \%$. The AC conductivity and ionic conductivity, as well as dielectric permittivity of plasticized PMMA/PVC-g-PMMA/Mg( $\left.\mathrm{ClO}_{4}\right)_{2}$ GPBE,s increased with frequency and $\mathrm{Mg}\left(\mathrm{ClO}_{4}\right)_{2}$ doping content. Ionic conductivity of the doped GPBEs can be achieved from $5.51 \times 10^{-5}$ to $4.42 \times 10^{-4}\left(\mathrm{~S}_{\mathrm{cm}} \mathrm{cm}^{-1}\right)$ using $\mathrm{Mg}\left(\mathrm{ClO}_{4}\right)_{2}$ contents in the range from 10 to $40 \mathrm{wt} . \%$. The doped GPBEs are thermally stable up to $100^{\circ} \mathrm{C}$ with very low weight losses. The GPBE doped with $20 \mathrm{wt} . \%$ of $\mathrm{Mg}\left(\mathrm{ClO}_{4}\right)_{2}$ can be used as a new type of electrolyte for developing $\mathrm{Mg}$ batteries.
\end{abstract}

\section{Introduction}

Nowadays, lithium batteries are widely used for energy storage devices in smart phones, tablets/laptops, electric vehicles, etc. $[1,2]$. However, fire and explosion accidents of lithium batteries have occasionally occurred worldwide, some of which caused serious threats to user's health [3-5]. The reasons for these accidents are known as the use of liquid electrolytes, the poor thermal stability of lithium salts, and the formation of oxygen in charging/recharging at high temperatures [3]. Therefore, it is necessary to develop new types of ionic batteries with low toxicity, greater safety, and lower cost than lithium batteries [5-11]. Over the past decades, gel polymer electrolytes have been extensively studied due to their high compliance, processability, mouldability, good electrode-electrolyte contact, and high ambient temperature conductivity. Besides, the increasing attention has been paid to the development of magnesium ion 
cells/batteries with the high specific capacity, efficiency, and good cyclability $[12,13]$. Gel polymer electrolytes can be produced when the polymer swells up in organic solvents or plasticizers, which can provide better contact with the electrode surface than the dry solid polymer electrolytes (free of solvents/plasticizers) [13].

Poly(vinyl chloride) (PVC) and their blends have been employed which used as gel polymer electrolytes [14-20]. Several studies have shown that the tensile properties, [15] thermal stability, [16] ionic conductivity, and [15] chargedischarge properties of PVC can be improved by the blending with poly(methyl methacrylate) (PMMA) or using graft copolymer-like PVC-graft-PMMA and plasticizers to form gel polymer blend (GPB) electrolytes [14, 20].

In our previous study, we have reported the mechanical and dielectrical properties of GPBEs doped with $\mathrm{Mg}\left(\mathrm{ClO}_{4}\right)_{2}$ salt [21]. It was found that plasticizers are very important to improve the ionic conductivity of the GPBEs. However, it is necessary to enhance the mechanical and dielectrical properties for the GPBEs to expand the applicability of the materials. In this study, a graft copolymer named PVC-gPMMA (PVCg) was synthesized and mixed with PMMA and plasticizers to prepare PMMA/PVCg gel polymer blend electrolytes. The graft copolymer was expected as a compatibilizer for improving mechanical and electrical properties of the GPBEs. The effects of magnesium perchlorate on these properties and morphology of the electrolytes were also investigated.

\section{Experimental}

2.1. Materials. Polyvinyl chloride (PVC, SG-660, $\mathrm{k}$ index of 65-67) is a commercial product of Plastic \& Chemical Corp., Ltd. (TPC Vina, Vietnam). Methyl methacrylate (MMA, 99\%), poly(methyl methacrylate) (PMMA, weight average molecular weight of 120000), and propylene carbonate (PC, 99.7\%) were purchased from Aldrich (USA). Tetrahydrofuran (THF, 99.7\%), chloroform $\left(\mathrm{CH}_{3} \mathrm{Cl}, 99.5 \%\right)$, and $\mathrm{Mg}\left(\mathrm{ClO}_{4}\right)_{2}$ were reagent grade products of Xilong Co., Ltd., China. Ethyl alcohol (ethanol, 99.7\%), methyl alcohol (methanol, 99.7\%), and dioctyl phthalate (DOP, 95\%) were provided by Duc Giang Chemical and Detergent powder Joint Stock Company, Vietnam. Chemicals were of analytical grade and used as received.

2.2. Preparation of Electrolyte Films. Graft copolymer of PVC-g-PMMA (labeled as PVCg) with the PMMA graft content of $20.3 \mathrm{wt} \%$ had been prepared as stated in the previous study [22]. As similarly, the weight ratio of PVC: PMMA was kept as $1: 1$ in this study. Therefore, the compositions of GPBEs were prepared as shown in Table 1, where the weight of PMMA in PVC-g-PMMA was calculated of $0.115 \mathrm{~g}$ and that of PVC was $0.45 \mathrm{~g}$, or PMMA: PVC weight ratio of $1: 1$. In an example of preparation of an electrolyte film, PMMA, PVCg, plasticizers, and $\mathrm{Mg}\left(\mathrm{ClO}_{4}\right)_{2}$ were charged in a flask containing THF. The mixture was stirred at $40^{\circ} \mathrm{C}$ for 4 hours to obtain a homogenous solution which was then poured into a $10 \times 10 \times 1(\mathrm{~cm})$ release paper. The THF solvent was allowed to evaporate naturally in a fume hood for
TABLE 1: Compositions and sample labels for electrolyte films doped with different $\mathrm{Mg}\left(\mathrm{ClO}_{4}\right)_{2}$ contents.

\begin{tabular}{lcccc}
\hline $\begin{array}{l}\text { Label of } \\
\text { sample }\end{array}$ & $\begin{array}{c}\text { PMMA } \\
(\mathrm{g})\end{array}$ & $\begin{array}{c}\text { PVCg } \\
(\mathrm{g})\end{array}$ & $\begin{array}{c}\mathrm{DOP} \\
+\mathrm{PC}(\mathrm{g})\end{array}$ & $\begin{array}{c}\mathrm{Mg}\left(\mathrm{ClO}_{4}\right)_{2} \\
(\mathrm{~g})\end{array}$ \\
\hline GPBE.0 & 0.335 & 0.565 & 1.800 & - \\
GPBE.10 & 0.335 & 0.565 & 1.800 & 0.300 \\
GPBE.20 & 0.335 & 0.565 & 1.800 & 0.675 \\
GPBE.30 & 0.335 & 0.565 & 1.800 & 1.157 \\
GPBE.40 & 0.335 & 0.565 & 1.800 & 1.800 \\
\hline
\end{tabular}

$24 \mathrm{~h}$, then complete drying in vacuum oven at $40^{\circ} \mathrm{C}$ for $24 \mathrm{~h}$. The collected film was stored in a desiccator for at least $24 \mathrm{~h}$ before characterizations. The compositions and sample labels are described in Table 1.

2.3. Characterization. FTIR spectra of all samples were performed on a Fourier transform infrared spectrometer (Nicolet/Nexus 670, USA) with 32 scans, $4 \mathrm{~cm}^{-1}$ resolution, and in wave number ranging from 400 to $4000 \mathrm{~cm}^{-1}$ at room temperature.

The tensile properties of the electrolyte samples were conducted on a universal testing machine (Zwick V.2.5, Germany) with a crosshead speed of $50 \mathrm{~mm} / \mathrm{min}$, in accordance with ASTM D882 for thin plastic films.

Complex dielectric properties (real part- $Z^{\prime}[R]$ and imaginary part $\left.-Z^{\prime \prime}[X]\right)$ of electrolyte films were measured by using an Agilent E4980A instrument at $R-X$ impedance parameters using the $16451 \mathrm{~B}$ test fixture, in the frequency range of $25 \mathrm{~Hz}-1 \mathrm{MHz}$ (according to the limit of the Agilent E4980A instrument), with a peak amplitude of $1.0 \mathrm{~V}$ and applied voltage to the ground electrode of $0 \mathrm{~V}$ (Earth ground), at room temperature $\left(24-28^{\circ} \mathrm{C}\right)$, as per ASTM D150 standard. Electrolyte films were sandwiched between stainless steel (SS) electrodes as the SS/GPBEs/SS configuration or $\mathrm{Mg}$ electrodes as the $\mathrm{SS} / \mathrm{Mg} / \mathrm{GPBEs} / \mathrm{Mg} / \mathrm{SS}$ configuration. $\mathrm{Mg}$ electrodes with a diameter of $5 \mathrm{~mm}$ were cut from the $\mathrm{Mg}$ sheet.

AC conductivity $(\sigma)$ and dielectric constant $(\varepsilon)$ of electrolyte films were determined from measured $R-X$ values (capacitive reactance and resistance of complex impedance) as the equations at every frequency $(f)$ : [23-25].

$$
\begin{aligned}
\sigma_{A C} & =\frac{1}{R} \times \frac{t}{A}, \\
\varepsilon & =\frac{1}{2 \pi f \varepsilon_{0}|X|} \times \frac{t}{A},
\end{aligned}
$$

where $t$ is the thickness of the electrolyte film, $A$ is the (contact) area of the working electrode (with $0.005 \mathrm{~m}$ in diameter), $f$ is the frequency, $|X|$ is the absolute value of $X$ (measured capacitive reactance), $R$ is the measured resistance component, and $\varepsilon_{0}$ is the vacuum permittivity $\left(8.854 \times 10^{-12}\right.$ $\mathrm{F} / \mathrm{m})$.

Morphology, element composition, and elemental mapping of the samples were analyzed by scanning electron microscopy (SEM) combined with energy dispersive X-ray 


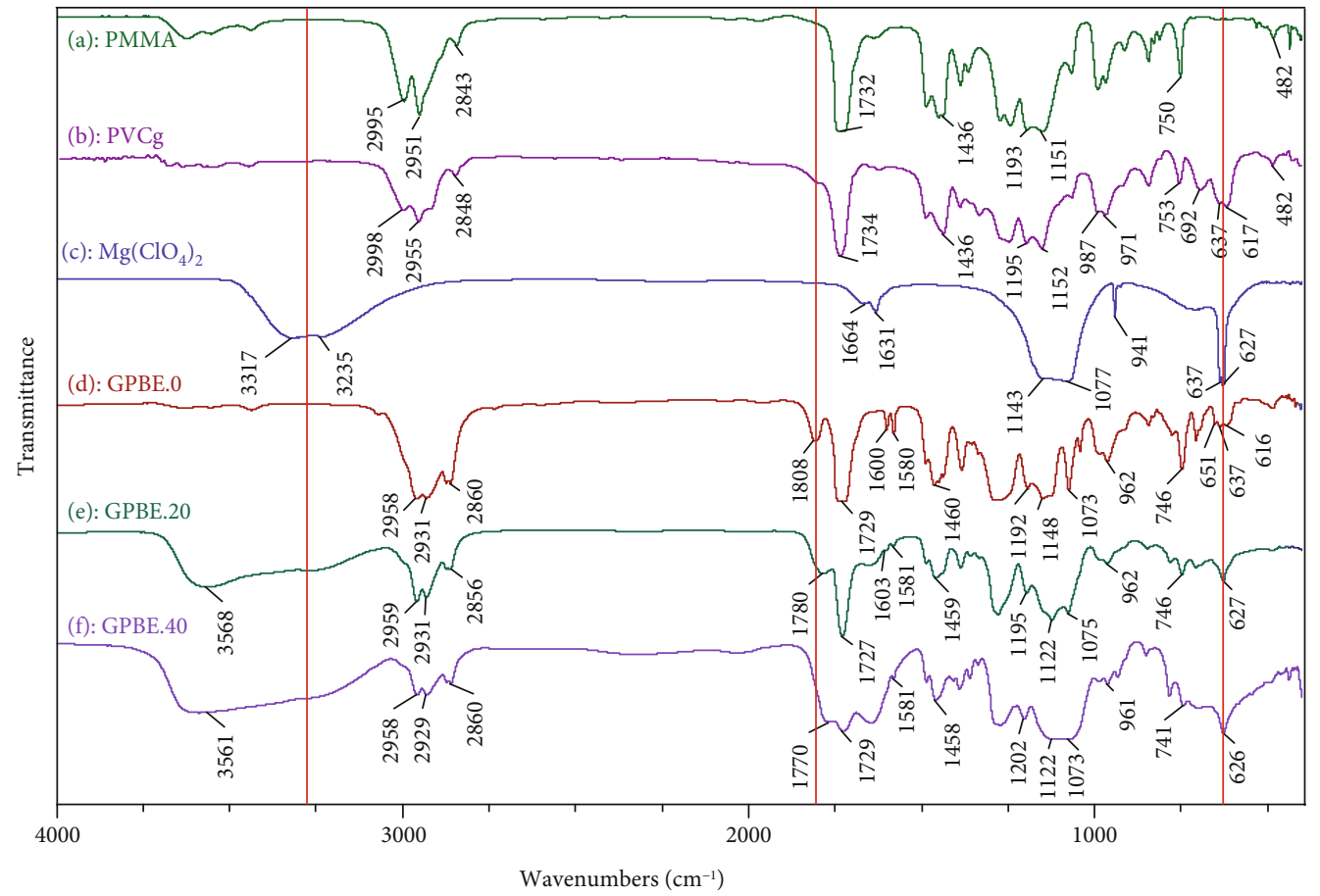

Figure 1: The FTIR spectra of (a) PMMA, (b) PVCg copolymer, (c) $\mathrm{Mg}\left(\mathrm{ClO}_{4}\right)_{2}$, and spectra of GPBEs with different $\left.\mathrm{Mg}(\mathrm{ClO})_{4}\right)_{2}$ contents.

TABLE 2: Band assignments for specific groups in FTIR spectra of PMMA, PVCg, GPBE.0, $\mathrm{Mg}\left(\mathrm{ClO}_{4}\right)_{2}$, GPBE.20, and GPBE.40 samples.

\begin{tabular}{|c|c|c|c|c|c|c|c|c|}
\hline \multirow[b]{2}{*}{ Vibration mode } & \multicolumn{8}{|c|}{ Vibration absorption in the wavenumber $\left(\mathrm{cm}^{-1}\right)$ for specific groups } \\
\hline & PMMA & PVCg & $\mathrm{Mg}\left(\mathrm{ClO}_{4}\right)_{2}$ & GBPE.0 & GBPE.10 & GBPE.20 & GBPE.30 & GBPE.40 \\
\hline$\nu \mathrm{C}=\mathrm{O}(\mathrm{PMMA})$ & 1732 & 1734 & - & 1729 & 1729 & 1729 & 1729 & 1727 \\
\hline$v \mathrm{C}=\mathrm{O}(\mathrm{PC})$ & - & - & - & 1808 & 1780 & 1780 & 1774 & 1770 \\
\hline$\delta \mathrm{C}=\mathrm{O}(\mathrm{PMMA})$ & 750 & 753 & - & 746 & 745 & 746 & 745 & 741 \\
\hline$\delta \mathrm{C}=\mathrm{O}(\mathrm{PC})$ & - & - & - & 771 & 779 & 778 & 778 & 780 \\
\hline \multirow{2}{*}{ Aromatic ring } & - & - & - & 1600 & 1601 & 1603 & 1601 & 1601 \\
\hline & & & & 1580 & 1580 & 1581 & 1580 & 1580 \\
\hline \multirow{2}{*}{$\delta \mathrm{CH}_{3}$} & 1484 & 1486 & - & 1487 & 1487 & 1485 & 1485 & 1483 \\
\hline & 1436 & 1436 & & 1460 & 1460 & 1459 & 1459 & 1457 \\
\hline$\delta \mathrm{CH}_{2}$ & 1387 & 1388 & - & 1383 & 1385 & 1385 & 1384 & 1388 \\
\hline$v \mathrm{C}-\mathrm{O}$ & 1272 & 1274 & - & 1275 & 1277 & 1276 & 1276 & 1276 \\
\hline \multirow[t]{2}{*}{$v \mathrm{Cl}-\mathrm{O} /$} & - & - & 1143 & - & - & - & - & - \\
\hline & - & - & 1077 & - & - & 1075 & 1075 & 1075 \\
\hline \multirow[t]{2}{*}{$v \mathrm{C}-\mathrm{Cl}$} & - & - & 637 & 616 & 627 & 627 & 627 & 626 \\
\hline & - & - & 627 & 637 & - & - & - & - \\
\hline
\end{tabular}

(EDX) spectroscopy (JSM-6510LV SEM instrument, Jeol, Japan).

Thermal Gravimetric Analysis (TGA) was carried out in a NETZSCH TG 209F1 (Germany) instrument to study the thermal degradation properties of the electrolyte under nitrogen gas with a flow rate of $40 \mathrm{ml} / \mathrm{min}$, from room temperature to $650^{\circ} \mathrm{C}$ with a heating rate of $10^{\circ} \mathrm{C} / \mathrm{min}$, and specimen weight of about 6-7 mg. All above measurements were carried out in laboratory rooms with relative humidity of $40-50 \%$, and the sample was measured right after removed from the vacuum environment.

\section{Results and Discussion}

3.1. FTIR Spectra. Figure 1 displays the FTIR spectra of the raw materials and synthesized samples. Referred to previous studies [22], it is very easy to assigned all absorption peaks for specific groups of PMMA (Figure 1(a)), PVCg (Figure 1(b)), and GPBE (Figure 1(c)). For more details, Table 2 lists some main band assignments for PMMA, PVC, and GBPE samples without and with magnesium perchlorate salt (20, 40 wt.\%). Comparing with the spectra of neat PMMA and PVCg, the spectrum of the GPBE.0 sample (Figure 1(d)) appears some 


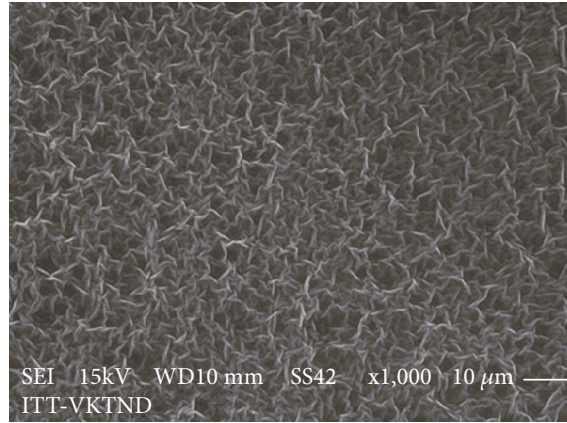

(a)

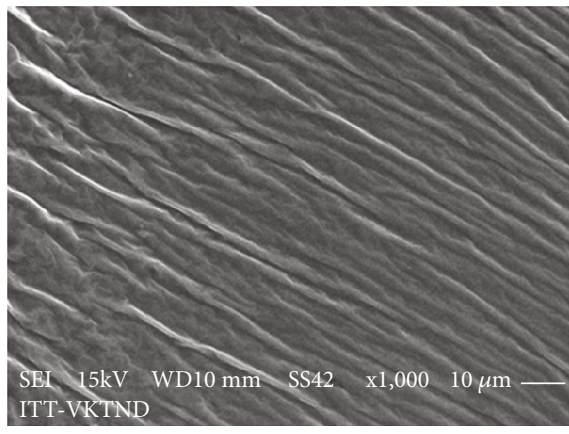

(c)

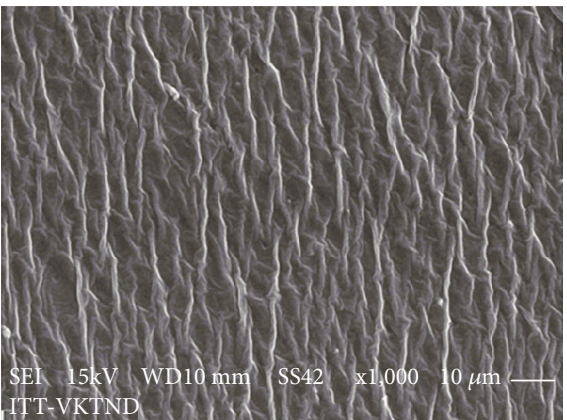

(b)

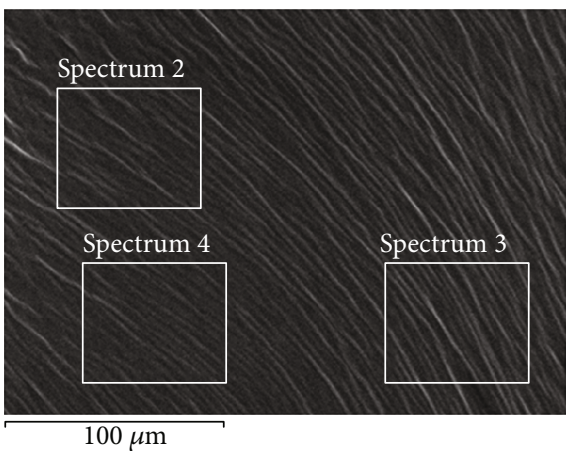

(d)

Figure 2: SEM images of (a) GPBE.0, (b) GPBE.10, and (c, d) GPBE.20 films.

Multielement EDS mapping (layered)

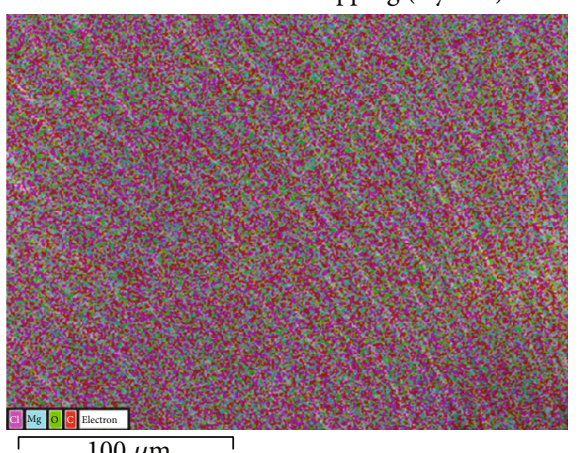

$100 \mu \mathrm{m}$

(a)

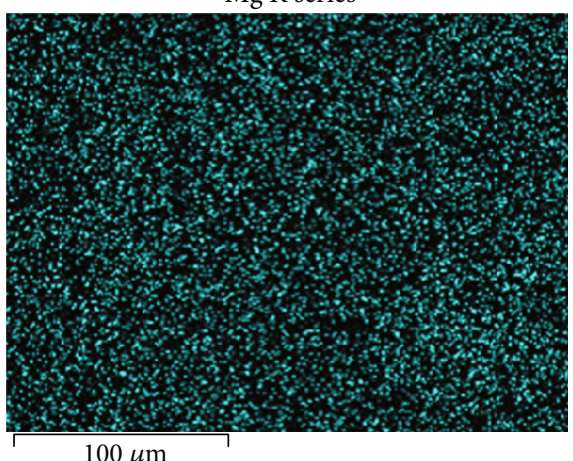

(c)
$\mathrm{Cl} \mathrm{K}$ series

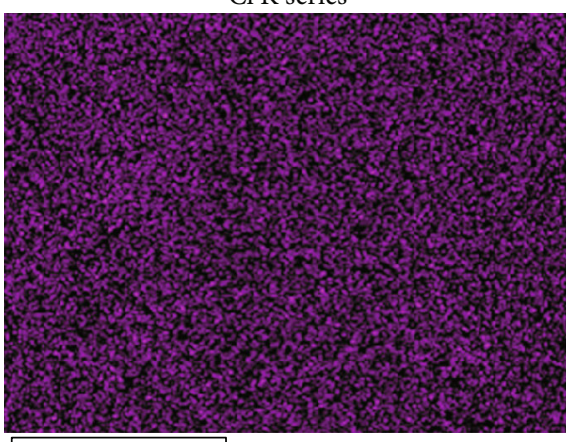

$100 \mu \mathrm{m}$

(b)

O K series

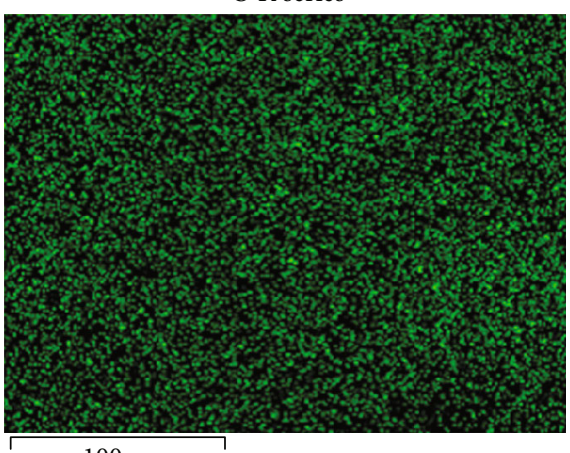

$100 \mu \mathrm{m}$

Figure 3: Single elemental mapping of the GPBE.20 film for C, O, Cl, and $\mathrm{Mg}$ atoms. 


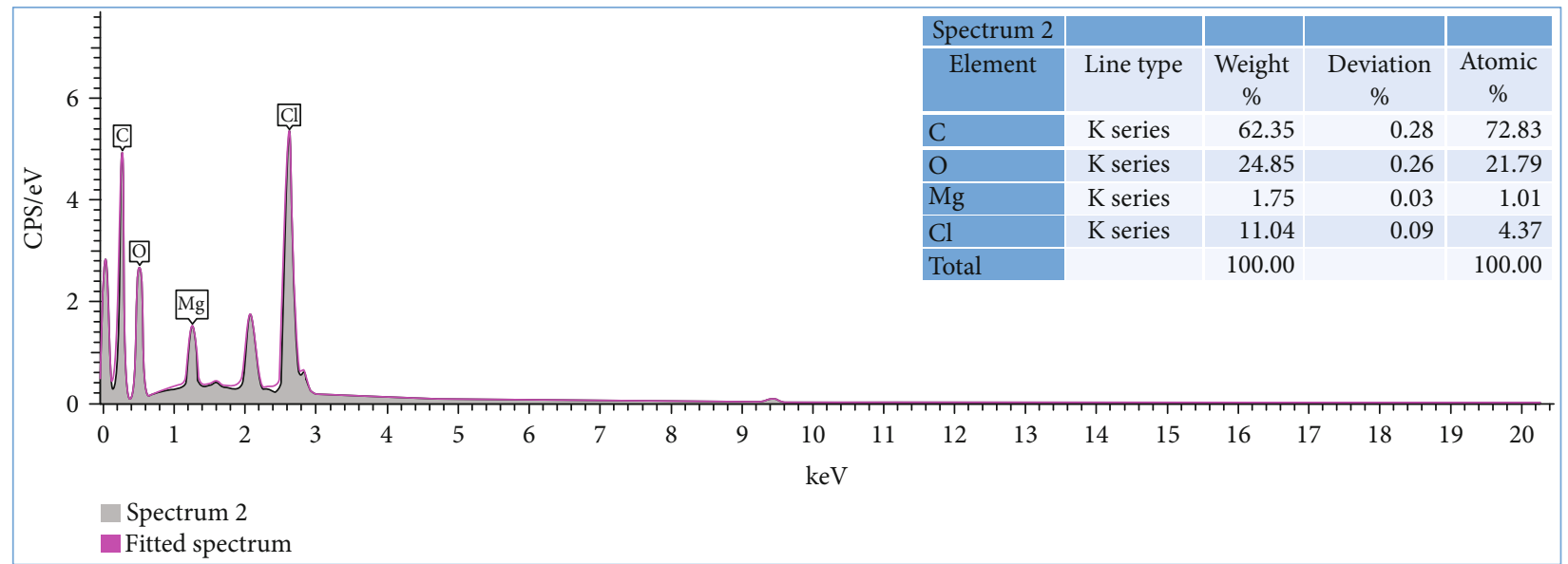

FIGURE 4: EDX spectrum of the GPBE.20 electrolyte film and analyzed composition table.

TABle 3: Tensile properties of GPBE films with and without $\mathrm{Mg}\left(\mathrm{ClO}_{4}\right)_{2}$.

\begin{tabular}{lccc}
\hline Label of sample & Young's modulus $(\mathrm{MPa})$ & Elongation at break (\%) & Tensile strength (MPa) \\
\hline GPBE.0 & 2.75 & 58 & 1.15 \\
GPBE.10 & 1.83 & 142 & 1.10 \\
GPBE.20 & 1.38 & 215 & 1.02 \\
GPBE.30 & 1.12 & 174 & 0.96 \\
GPBE.40 & 0.86 & 167 & 0.85 \\
\hline
\end{tabular}

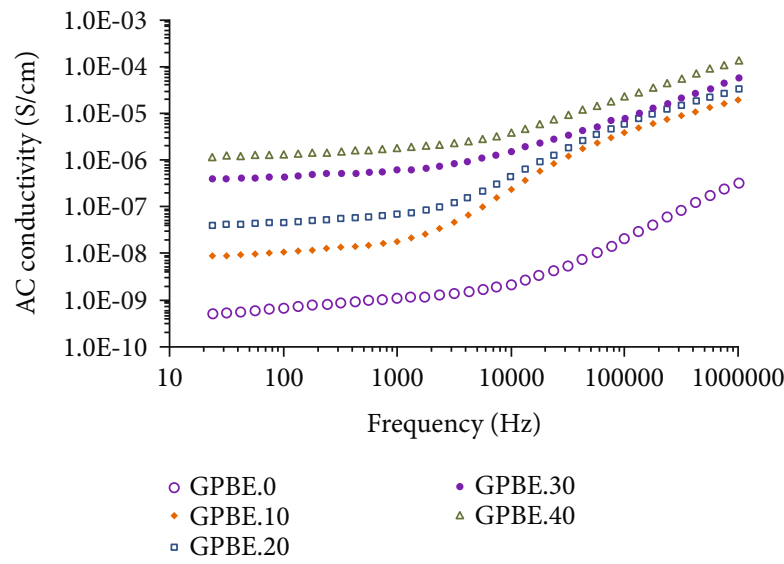

(a)

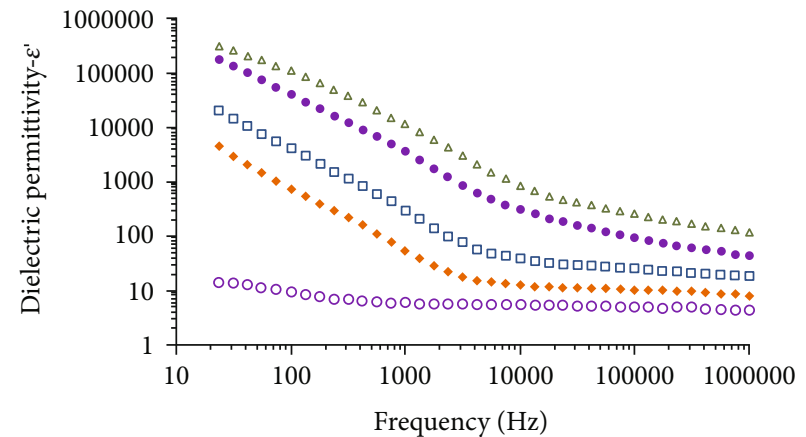

- GPBE.0
GPBE.10
- GPBE. 20

- GPBE.30

$\triangle$ GPBE.40

(b)

FIGURE 5: Dielectric properties of GPBEs as functions of frequency (a) AC conductivity and (b) dielectric permittivity, with the SS/GPBE/SS electrode configuration at $25^{\circ} \mathrm{C}$.

new peaks attributed to the presence of plasticizers, the peaks at $1805 \mathrm{~cm}^{-1}$ and $1732 \mathrm{~cm}^{-1}$ can be assigned for $\mathrm{C}=\mathrm{O}$ stretching vibrations $(v)$ of the PC plasticizer and PMMA, and the doublet at 1600 and $1580 \mathrm{~cm}^{-1}$ is assigned for aromatic ring of the DOP plasticizer (Table 2 column 5), whereas comparing with spectrum of the GPBE.0 sample, the FTIR spectra of GPBEs doped with different weight amounts of $\mathrm{Mg}\left(\mathrm{ClO}_{4}\right)_{2}$ (Figures 1(e) and 1(f)) show some differences. The first is the strong absorption band of $v(\mathrm{OH})$ in the wavenumber region from 3700 to $3100 \mathrm{~cm}^{-1}$ due to the moisture absorption of $\mathrm{Mg}\left(\mathrm{ClO}_{4}\right)_{2}$ from the air during FTIR recording. The second difference is the disappearance of three peaks (651, 637 , and $616 \mathrm{~cm}^{-1}$ ), instead of only one peak at $627 \mathrm{~cm}^{-1}$ which appeared in the region of $660-600 \mathrm{~cm}^{-1}$. In addition, the band attributed to $\mathrm{C}=\mathrm{O}$ of $\mathrm{PC}$ appearing at $1808 \mathrm{~cm}^{-1}$ in spectrum of GPBE0 is shifted to 1780 and $1770 \mathrm{~cm}^{-1}$ in spectrum of GPBE.20 and GPBE.40, respectively. This shift increases with increasing $\mathrm{Mg}\left(\mathrm{ClO}_{4}\right)_{2}$ content, indicating the strong interactions between $\mathrm{Mg}\left(\mathrm{ClO}_{4}\right)_{2}$ and organic moieties (polymers and plasticizers) in the electrolytes. 


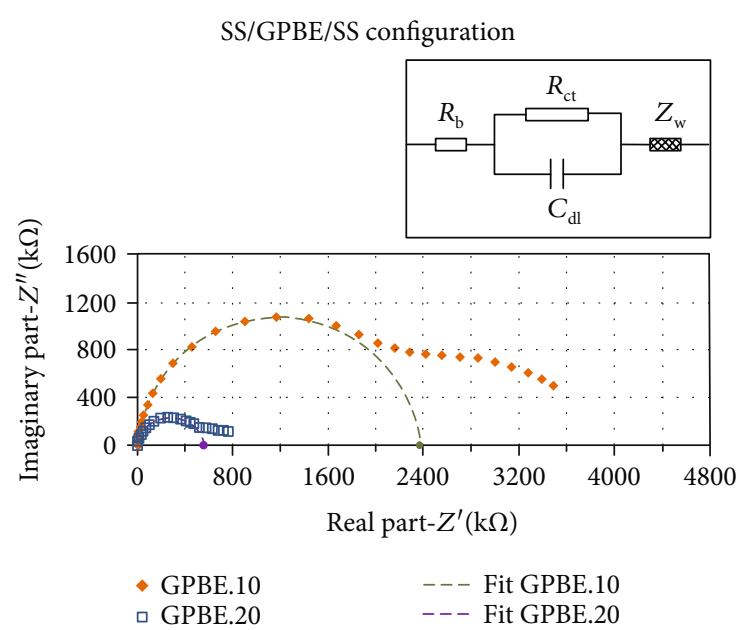

(a)

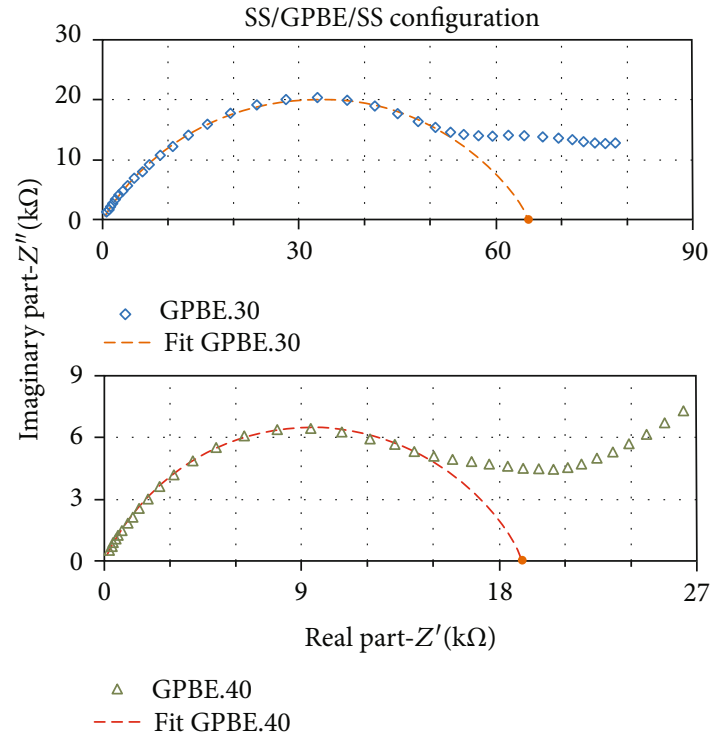

(b)

Figure 6: Nyquist plot and optimized fitting semicircles of GPBEs doped with different $\mathrm{Mg}\left(\mathrm{ClO}_{4}\right)_{2}$ contents.

3.2. Surface Morphology of Electrolyte Films. Figure 2 represents the SEM images of GPBE.0, GPBE.10, and GPBE.20 films. It can be seen that there are wrinkles on the surfaces of two kinds of samples (undoped and doped with magnesium salt), which are caused by the high flexibility of the films containing high plasticizer content. It was reported that PMMA/PVC blend films have craters or islands due to the immiscibility of ethylene/propylene carbonate plasticizer with PVC, which caused the separation of the PVC-rich phase and plasticizer-rich phase [26]. In order to improve the miscibility of plasticizer with the PMMA/PVC blend, ethylene carbonate was replaced by DOP which is known as one of the best plasticizer for PVC; moreover, PVC-g-PMMA graft copolymer was also employed in this study. As a result, the SEM images of new GPBEs clearly reveal that no craters or islands were observed on the surface of GPBEs. In addition, it is also interesting to see that the number of wrinkles on the surface of the $\mathrm{Mg}\left(\mathrm{ClO}_{4}\right)_{2}$-doped electrolyte film decreases with increasing $\mathrm{Mg}$ salt content.

To clarify the phase compositions at the wrinkles and the surface of the GPBE samples, elemental mapping of the GPBE.20 sample at its surface was conducted. In comparison with the original SEM image (Figure 2(d)) that was selected for EDS analysis, Figure 3(a) shows that the main chemical elements of GPBE.20 including $\mathrm{Mg}, \mathrm{C}, \mathrm{O}$, and $\mathrm{Cl}$ are all appeared and regularly distributed in its layered EDS mapping image, even at the wrinkles. Other EDS mapping images of single elements such as $\mathrm{Cl}, \mathrm{Mg}$, and $\mathrm{O}$ also confirm their regular distributions in the GPBE.20 sample. In other words, the wrinkles are not the interphase, and there is not any phase separation in the electrolyte sample. It means that using PVC-g-PMMA and DOP can improve the compatibility for the PMMA/PVC blend (50:50 wt./wt.).

Figure 4 displays a selected EDX spectrum of the GPBE.20 electrolyte film and the composition table result. The chemical elements of the electrolyte were detected with

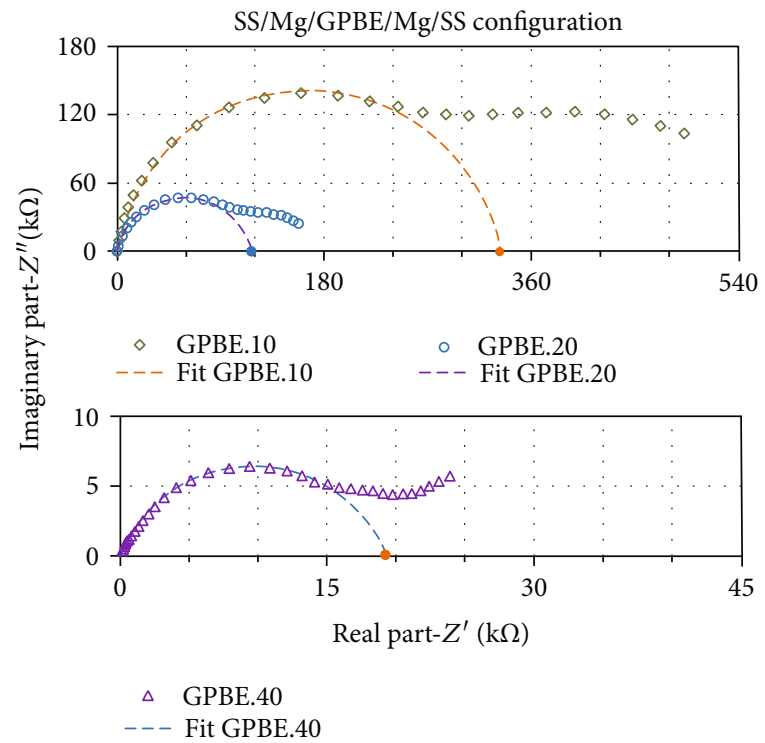

FIGURE 7: Nyquist plot and optimized fitting semicircles of GPBEs doped with different $\mathrm{Mg}\left(\mathrm{ClO}_{4}\right)_{2}$ contents.

relevant peaks labeled with $\mathrm{C}, \mathrm{O}, \mathrm{Mg}$, and $\mathrm{Cl}$. It is noted that the unlabeled peak (between $\mathrm{Mg}$ and $\mathrm{Cl}$ peaks) is of $\mathrm{Pt}$ coat and not taken into account. The table result (inside Figure 4) verifies that magnesium atom appears on the surface of the electrolyte films (1.75wt.\%) with lower concentration than those in the bulk (mathematically evaluated as 2.31 wt.\%).

3.3. Tensile Properties. Table 3 shows that Young's modulus of GPBE films strongly decreases from 2.75 to $0.65 \mathrm{MPa}$ with increasing $\mathrm{Mg}\left(\mathrm{ClO}_{4}\right)_{2}$ contents from 0 to $40 \mathrm{wt}$ \%, and their tensile strength also decreases from 1.72 to $0.84 \mathrm{MPa}$. In fact, these free-standing films can be commonly mounted in the 
TABLE 4: The evaluated values $R_{b}, R_{\mathrm{ct}}$, and ionic conductivities of the GPBEs.

\begin{tabular}{lcccccc}
\hline & \multicolumn{3}{c}{ SS/GBPE/SS electrode configuration } & \multicolumn{3}{c}{ SS/Mg/GBPE/Mg/SS electrode configuration } \\
Sample label & $R_{b}(\Omega)$ & $R_{c t}(\Omega)$ & $\sigma_{\text {ion }}(\mathrm{S} / \mathrm{cm})$ & $R_{b}(\Omega)$ & $R_{c t}(\Omega)$ & $\sigma_{\text {ion }}(\mathrm{S} / \mathrm{cm})$ \\
\hline GPBE.10 & 544.4 & $2.37 \times 10^{6}$ & $5.51 \times 10^{-5}$ & 268.8 & $2.90 \times 10^{5}$ & $1.14 \times 10^{-4}$ \\
GPBE.20 & 345.0 & $5.57 \times 10^{5}$ & $8.86 \times 10^{-5}$ & 120.0 & $1.17 \times 10^{5}$ & $2.55 \times 10^{-4}$ \\
GPBE.30 & 139.8 & $6.51 \times 10^{4}$ & $2.19 \times 10^{-4}$ & - & - & - \\
GPBE.40 & 97.1 & $1.90 \times 10^{4}$ & $3.15 \times 10^{-4}$ & 69.2 & $1.88 \times 10^{4}$ & $4.42 \times 10^{-4}$ \\
\hline
\end{tabular}

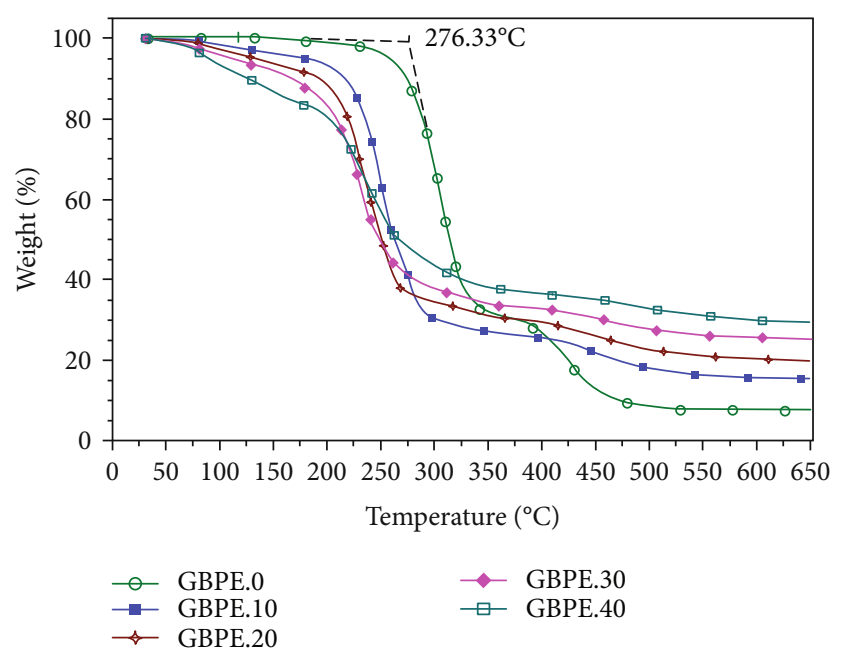

FIGURE 8: TGA diagrams of GPBE.0 and GPBE samples.

tensile test machine. The elongation at break of $\mathrm{Mg}\left(\mathrm{ClO}_{4}\right)_{2}$ doped GPBEs is higher than that of the undoped GPBEs and reaches the highest value of $215 \%$ with $20 \mathrm{wt} . \%$-doped content. In comparison with the previous study, tensile strength and modulus of present GPBEs (using PVC-gPMMA) are several folders higher than plasticized PMMA/PVC/Mg $\left(\mathrm{ClO}_{4}\right)_{2}$ electrolytes with equal salt contents. It demonstrates that the PVC-g-PMMA graft copolymer has played an important role as a compatibilizer to increase the adhesion between polymers and plasticizers.

3.4. Dielectric Properties. Figure 5 displays logarithm plots of AC conductivity and dielectric permittivity as a function of frequency (from $25 \mathrm{~Hz}$ to $1 \mathrm{MHz}$ ) for the GPBEs with different doping contents of $\mathrm{Mg}\left(\mathrm{ClO}_{4}\right)_{2}$. Figure 5(a) indicates that AC conductivity of all doped GPBEs increases with frequency and with magnesium salt concentration. The AC conductivities of doped GPBEs are several orders higher than undoped GPBE (GPBE.0). For example, the AC conductivity at $1 \mathrm{kHz}$ of neat GPBE. 0 is about $1.07 \times 10^{-9} \mathrm{~S} / \mathrm{cm}$. However, the values of GPBE.10, GPBE.20, GPBE.30, and GPBE.40 samples are of $1.83 \times 10^{-8}, 6.86 \times 10^{-7}, 6.03 \times 10^{-7}$, and $1.83 \times 10^{-6} \mathrm{~S} / \mathrm{cm}$, respectively. Figure 5(b) shows the strongly increase of dielectric permittivity of $\mathrm{Mg}\left(\mathrm{ClO}_{4}\right)_{2}$-doped electrolytes with the salt concentration. It should be noted that the weights of polymers and plasticizers (Table 3 ) are kept the same for all GPBEs. The enhancements in AC conductivity and dielectric permittivity are only related to the increase of the ion carrier concentration, which are generated by the electrolysis of the magnesium salt in the GPBEs.

Figures 6 and 7 display the Nyquist complex impedance plots of GPBEs with different doping contents of $\mathrm{Mg}\left(\mathrm{ClO}_{4}\right)_{2}$ using SS/GPBE/SS and SS/Mg/GPBE/Mg/SS electrode configurations, in the range from $25 \mathrm{~Hz}$ to $1 \mathrm{MHz}$ at room temperature. The impedance plots exhibit two regions, a part of semicircle and a tail, which could be modelled to the equivalent circuit drawn inside Figure 6(a), (where $R_{b}$ is a bulk resistance, $C_{\mathrm{dl}}$ is a double-layer capacitor, $R_{\mathrm{ct}}$ is a charge transfer resistance, and $Z_{w}$ is an interfacial impedance of GPBEs) [23]. Although the first region is not a full semicircle, when completed by fitting, the resistances $\left(R_{\mathrm{ct}}, R_{b}\right)$ can be evaluated via the intercepts of the semicircle with the real part axis at low- and high-frequency regions, respectively. It is easy to recognize that the diameters of the fitted semicircles $\left(\sim 2 R_{\mathrm{ct}}\right.$ resistances) are reduced by increasing $\mathrm{Mg}\left(\mathrm{ClO}_{4}\right)_{2}$ doping contents.

For more details, Table 4 shows the evaluated values of $R_{\mathrm{ct}}$ and $R_{b}$ of GPBE films from Figures 6 and 7. For the SS/GPBE/SS configuration, obtained results indicate that $R_{\mathrm{ct}}$ and $R_{b}$ of electrolyte samples decrease with increasing salt content from 10 to $40 \mathrm{wt} . \%$. Based on equation (1), the ionic conductivity of GPBEs doped with $\mathrm{Mg}\left(\mathrm{ClO}_{4}\right)_{2}$ (GPBE.10, 20, $30,40)$ increases from $5.51 \times 10^{-5}$ to $3.15 \times 10^{-4}\left(\mathrm{~S}_{\mathrm{cm}} \mathrm{cm}^{-1}\right)$. With the SS/Mg/GPBE/Mg/SS configuration, obtained results also show a similar decrease of $R_{c t}$ and $R_{b}$ of electrolyte samples with increasing the salt content. However, the lower value of $R_{\mathrm{ct}}$ for the $\mathrm{SS} / \mathrm{Mg} / \mathrm{GPBE}$ configuration at the same content of $\mathrm{Mg}\left(\mathrm{ClO}_{4}\right)_{2}$ confirmed that equilibrium was established between $\mathrm{Mg}$ metal and $\mathrm{Mg}^{2+}$ ions in the GPPE [27]. Table 4 also shows that the intercept $\left(R_{b}\right)$ values using the $\mathrm{SS} / \mathrm{Mg} / \mathrm{GPBE}$ configuration are higher than using for the GPBE samples with the SS/GPBE configuration.

3.5. Thermal Stability. Figure 8 illustrates the TGA diagrams of the undoped (or neat) GBPE and the GPBEs that were doped with magnesium perchlorate salt at different loadings. Table 5 displays the thermo analysis results from the above TGA diagrams. Figure 8 and Table 5 clearly present some differences between the undoped GPBE sample (GPBE.0) and doped GBPE samples (GPBE.10, 20, 30, 40); in other words, magnesium perchlorate affects the thermal stability of the neat GPBE. In the temperature region below $200^{\circ} \mathrm{C}$, the TGA line of the GPBE.0 sample keeps almost constant, which indicates it is thermo-stable in this temperature range. Meanwhile, the TGA curves of doped GPBEs show the first weight loss in this temperature region, due to the removal of 
TABLE 5: Thermal parameters of GPBE films with and without $\mathrm{Mg}\left(\mathrm{ClO}_{4}\right)_{2}$.

\begin{tabular}{|c|c|c|c|c|c|}
\hline Analysis result\sample & GPBE.0 & GPBE.10 & GPBE.20 & GPBE.30 & GPBE.40 \\
\hline Onset temperature $\left({ }^{\circ} \mathrm{C}\right)$ & 276.3 & 229.0 & 212.2 & 208.2 & 207.7 \\
\hline Weight at $75^{\circ} \mathrm{C}(\%)$ & 100 & 99.49 & 98.88 & 97.86 & 97.33 \\
\hline Weight at $100^{\circ} \mathrm{C}(\%)$ & 100 & 98.35 & 97.28 & 95.97 & 93.33 \\
\hline Weight at $200^{\circ} \mathrm{C}(\%)$ & 98.93 & 93.10 & 88.43 & 83.66 & 80.48 \\
\hline Weight at $400^{\circ} \mathrm{C}(\%)$ & 26.86 & 25.56 & 29.33 & 32.8 & 36.7 \\
\hline Weight at $650^{\circ} \mathrm{C}(\%)$ & 7.641 & 15.49 & 19.95 & 25.31 & 29.3 \\
\hline
\end{tabular}

adsorbed water [28]. Table 5 shows that the weight loss at $150^{\circ} \mathrm{C}$ of the doped GPBEs increases with increasing magnesium salt contents. This may result from the present of $\mathrm{Mg}\left(\mathrm{ClO}_{4}\right)_{2}$ as a weak Lewis acid property which can accelerate the degradation of PVC. However, with temperature lower than $100^{\circ} \mathrm{C}$, the GPBE. 10 and GBPE.20 samples are thermally stable with low weight losses, e.g., $1.65 \mathrm{wt} . \%$ and 2.72 wt.\%, respectively.

In the temperature region from 200 to $650^{\circ} \mathrm{C}$, both two types of undoped and doped electrolyte samples undergo thermal degradation of organic moieties and decomposition of magnesium salt. In this temperature range, the GPBE.0 sample undergoes degradation with two distinct stages, the first stage starts from $220^{\circ} \mathrm{C}$ to $330^{\circ} \mathrm{C}$ with the onset temperature of $277.4^{\circ} \mathrm{C}$, and this can be attributed to the dehydrochlorination of PVC and unsaturated groups of PMMA [16, $29,30]$. The second stage starts from 330 to $650^{\circ} \mathrm{C}$ with char residual of about 8 wt. $\%$. In $200-280^{\circ} \mathrm{C}$ range, the TGA curves of doped electrolyte samples also show their second stages of thermal degradation, in which their curves shift to lower temperature compared to that of the GPBE.0 sample. This means that magnesium perchlorate salt strongly reduces the thermal stability of the plasticized PVCg/PMMA blend. Table 5 shows that the onset temperatures of doped electrolyte samples strongly reduce when increasing the salt contents. This phenomenon can be due to the decomposition of perchlorate groups that has generated the oxide atoms which accelerate the oxidation and dehydrochlorination of PVC as well as the degradation of other organic substances in the GPBEs.

It should be noted that stabilizers had not been mixed with PVC while preparing plasticized PVC-gPMMA/PMMA blend electrolytes in order to investigate the sole effect of magnesium perchlorate on its thermal stability and other electrical properties. This suggests that stabilizers for PVC should be used in order to limit the thermal stability of the $\mathrm{Mg}\left(\mathrm{ClO}_{4}\right)_{2}$-doped GPBEs.

\section{Conclusion}

$\mathrm{Mg}\left(\mathrm{ClO}_{4}\right)_{2}$-doped GPBEs have been prepared by using the solution casting method. The obtained results showed that PVC-g-PMMA played an important role as the compatibilizer for enhancing mechanical and dielectrical properties of GPBEs. Some observable changes in FTIR spectra of GPBEs indicate the molecular interactions between the salt and plasticizers/polymers in the GPBEs. SEM images and EDX map- ping technique demonstrated that $\mathrm{Mg}\left(\mathrm{ClO}_{4}\right)_{2}$ regularly distributed into the plasticizers/polymers system. Young's modulus and tensile strength of GPBEs strongly reduced with the loading $\mathrm{Mg}\left(\mathrm{ClO}_{4}\right)_{2}$ content. The elongation at break of the doped GPBEs was higher than the undoped GPBE and reached the highest value of $215 \%$ at the doping content of 20 wt.\%. The AC and ionic conductivities of GPBEs increased with the loading $\mathrm{Mg}\left(\mathrm{ClO}_{4}\right)_{2}$ content. Magnesium perchlorate reduced the thermal stability of GPBE films; however, the doped GPBEs are thermally stable with low weight losses at temperature lower than $100^{\circ} \mathrm{C}$. Stabilizers and anhydrous magnesium perchlorate and water-free media should be used when preparing GBPE films for the next studies. In overall consideration of mechanical, dielectrical properties and thermal stability of the GPBEs, the plasticized PMMA/PVC-gPMMA with 20 wt. $\% \mathrm{Mg}\left(\mathrm{ClO}_{4}\right)_{2}$ can be chosen as a best candidate of electrolyte for magnesium batteries with working temperature lower than $100^{\circ} \mathrm{C}$.

\section{Data Availability}

The data used to support the findings of this study are included within the article.

\section{Conflicts of Interest}

All authors declare that they have no conflicts of interest.

\section{Acknowledgments}

This work is completed under the financial support from the Vietnam Academy of Science and Technology (VAST) under grant number VAST03.05/20-21.

\section{References}

[1] J. Bao, C. Tao, R. Yu, M. Gao, Y. Huang, and C. Chen, "Solid polymer electrolyte based on waterborne polyurethane for all-solid-state lithium ion batteries," Journal of Applied Polymer Science, vol. 134, no. 48, 2017.

[2] A. Manthiram, X. Yu, and S. Wang, "Lithium battery chemistries enabled by solid-state electrolytes," Nature Reviews Materials, vol. 2, no. 4, 2017.

[3] Q. Wang, J. Sun, and G. Chu, Lithium ion Battery Fire and Explosion, in Fire Safety Science - Proceedings of the Eighth International Symposium, Tsinghua University, Beijing, China, 2005. 
[4] M. S. Apitanawit, Influence of the Samsung Galaxy Note 7's Battery Problem on Consumer Perception and Intention to Purchase Samsung Smartphone in the Future, Master Science Program in Marketing, Thammasat University, 2016.

[5] K. Liu, Y. Liu, D. Lin, A. Pei, and Y. Cui, "Materials for lithium-ion battery safety," Science advances, vol. 4, no. 6, p. eaas $9820,2018$.

[6] D. Liu, W. Zhu, Z. Feng, A. Guerfi, A. Vijh, and K. Zaghib, "Recent progress in sulfide-based solid electrolytes for Li-ion batteries," Materials Science and Engineering B, vol. 213, pp. 169-176, 2016.

[7] L. Yue, J. Ma, J. Zhang et al., "All solid-state polymer electrolytes for high-performance lithium ion batteries," Energy Storage Materials, vol. 5, pp. 139-164, 2016.

[8] U. Ali, K. J. B. A. Karim, and N. A. Buang, "A review of the properties and applications of poly (methyl methacrylate) (PMMA)," Polymer Reviews, vol. 55, no. 4, pp. 678-705, 2015.

[9] S. W. Moore and P. J. Schneider, A Review of Cell Equalization Methods for Lithium Ion and Lithium Polymer Battery Systems, Society of Automotive Engineers, Inc., 2001.

[10] P. Saha, M. K. Datta, O. I. Velikokhatnyi, A. Manivannan, D. Alman, and P. N. Kumta, "Rechargeable magnesium battery: current status and key challenges for the future," Progress in Materials Science, vol. 66, pp. 1-86, 2014.

[11] P. Yao, H. Yu, Z. Ding et al., "Review on polymer-based composite electrolytes for Lithium batteries," Frontiers in Chemistry, vol. 7, pp. 522-522, 2019.

[12] J. Wang, S. Song, S. Gao, R. Muchakayala, R. Liu, and Q. Ma, "Mg-ion conducting gel polymer electrolyte membranes containing biodegradable chitosan: preparation, structural, electrical and electrochemical properties," Polymer Testing, vol. 62, pp. 278-286, 2017.

[13] R. Manjuladevi, M. Thamilselvan, S. Selvasekarapandian, R. Mangalam, M. Premalatha, and S. Monisha, "Mg-ion conducting blend polymer electrolyte based on poly(vinyl alcohol)-poly (acrylonitrile) with magnesium perchlorate," Solid State Ionics, vol. 308, pp. 90-100, 2017.

[14] N.-S. Choi and J.-K. Park, "New polymer electrolytes based on PVC/PMMA blend for plastic lithium-ion batteries," Electrochimica Acta, vol. 46, no. 10-11, pp. 1453-1459, 2001.

[15] H.-S. Han, H.-R. Kang, S.-W. Kim, and H.-T. Kim, "Phaseseparated polymer electrolyte based on poly(vinyl chloride)/poly(ethyl methacrylate) blend," Journal of Power Sources, vol. 112, no. 2, pp. 461-468, 2002.

[16] S. Ramesh, C.-W. Liew, E. Morris, and R. Durairaj, "Effect of PVC on ionic conductivity, crystallographic structural, morphological and thermal characterizations in PMMA-PVC blend-based polymer electrolytes," Thermochimica Acta, vol. 511, no. 1-2, pp. 140-146, 2010.

[17] M. P. Scott, M. Rahman, and C. S. Brazel, "Application of ionic liquids as low-volatility plasticizers for PMMA," European Polymer Journal, vol. 39, no. 10, pp. 1947-1953, 2003.

[18] S. Rajendran and T. Uma, "Effect of $\mathrm{ZrO}_{2}$ on conductivity of PVC- $\mathrm{LiBF}_{4}-\mathrm{DBP}$ polymer electrolytes," Materials Letters, vol. 44, no. 3-4, pp. 208-214, 2000.

[19] S. Ramesh, G. B. Teh, R.-F. Louh, Y. K. Hou, P. Y. Sin, and L. J. $\mathrm{Yi}$, "Preparation and characterization of plasticized high molecular weight PVC-based polymer electrolytes," Sadhana, vol. 35, no. 1, pp. 87-95, 2010.

[20] W. Li, M. Yuan, and M. Yang, "Dual-phase polymer electrolyte with enhanced phase compatibility based on Poly(MMA-g-
PVC)/PMMA," European Polymer Journal, vol. 42, no. 6, pp. 1396-1402, 2006.

[21] D. Q. Tham, T. T. Mai, T. Hoang et al., "Preparation and characterizations of plasticized $\mathrm{PMMA} / \mathrm{PVC} / \mathrm{Mg}(\mathrm{ClO}<\mathrm{sub}>4</$ sub $>)<-$ sub $>2</$ sub $>$ electrolytes," Vietnam Journal of Science and Technology, vol. 57, no. 5, pp. 559-571, 2019.

[22] D. Q. Tham, T. T. Mai, T. Hoang, N. T. T. Trang, N. T. Chinh, and D. X. Thang, "Preparation and FTIR studies of PMMA/PVC polymer blends, PVC-g-PMMA graft copolymers and evaluating graft content," Vietnam Journal of Science and Technology, vol. 57, no. 1, pp. 32-41, 2019.

[23] G. Girish Kumar and N. Munichandraiah, "Poly(methylmethacrylate)-magnesium triflate gel polymer electrolyte for solid state magnesium battery application," Electrochimica Acta, vol. 47, no. 7, pp. 1013-1022, 2002.

[24] K. M. Anilkumar, B. Jinisha, M. Manoj, and S. Jayalekshmi, "Poly(ethylene oxide) (PEO) - poly(vinyl pyrrolidone) (PVP) blend polymer based solid electrolyte membranes for developing solid state magnesium ion cells," European Polymer Journal, vol. 89, pp. 249-262, 2017.

[25] S. Ramesh, "Miscibility studies of PVC blends (PVC/PMMA and PVC/PEO) based polymer electrolytes," Solid State Ionics, vol. 148, no. 3-4, pp. 483-486, 2002.

[26] A. M. Stephan, T. P. Kumar, N. G. Renganathan, S. Pitchumani, R. Thirunakaran, and N. Muniyandi, "Ionic conductivity and FT-IR studies on plasticized PVC/PMMA blend polymer electrolytes," Journal of Power Sources, vol. 89, no. 1, pp. 80-87, 2000.

[27] G. G. Kumar and N. Munichandraiah, "Reversibility of $\mathrm{Mg} / \mathrm{Mg} 2+$ couple in a gel polymer electrolyte," Electrochimica Acta, vol. 44, no. 15, pp. 2663-2666, 1999.

[28] D. J. Devlin and P. J. Herley, "Thermal decomposition and dehydration of magnesium perchlorate hexahydrate," Thermochimica Acta, vol. 104, pp. 159-178, 1986.

[29] D. Q. Tham, T. Hoang, N. V. Giang, N. T. K. Dung, and I. Chung, "Synthesis and characterization of (4-arm-starPMMA)/PMMA-g-SiO 2 hybrid nanocomposites," Green Processing and Synthesis, vol. 7, no. 5, pp. 391-398, 2018.

[30] J. Chen, X. A. Nie, J. C. Jiang, and Y. H. Zhou, "Thermal degradation and plasticizing mechanism of poly (vinyl chloride) plasticized with a novel cardanol derived plasticizer," IOP Conference Series: Materials Science and Engineering, vol. 292, p. 012008, 2018. 